\title{
HISTORIA ESPIRITUAL Y SENSIBILIDAD ESTÉTICA: EL OTOÑO DE LA EDAD MEDIA DE JOHAN HUIZINGA
}

\author{
Spiritual History and Aesthetic Sensibility: \\ Johan Huizinga's The Autumn of the Middle Age \\ Ricardo PÉREZ GÓMEZ ${ }^{1}$ \\ Universidad Católica Andrés Bello (Caracas, Venezuela)
}

\section{Resumen}

El presente ensayo analiza la obra El otoño de la Edad Media del historiador holandés Johan Huizinga, a la luz de la interpretación histórica de una época a partir de una heurística basada en el arte y una hermenéutica basada en la estética. Para ello, exponemos los postulados principales que sobre la investigación histórica sostenía Huizinga y se comparan con otros enfoques, recogiendo las críticas más relevantes que ha recibido tanto el autor como la obra estudiada. Se explica en detalle cómo dichos postulados se hacen patentes en algunas categorías de análisis expuestas en la obra, tales como el espíritu caballeresco, el amor cortés, la muerte y el pensamiento simbólico. Se hace especial énfasis en estudiar las particulares heurística y hermenéutica propuestas por Huizinga en el análisis del pasado a partir de las manifestaciones artísticas y la vigencia que éstas pueden tener en la actualidad.

Palabras clave: Huizinga, historiografía, historia cultural, Edad Media

\section{Abstract}

This essay discusses the analysis and interpretation about a historic epoch made by Johan Huizinga, the Dutch historian, in his book The Autumn of the Middle Age, based on Huizinga's own approach focused on art and culture. Main concepts of Huizinga about the history as a science are exposed and compared against others coming from historians of different thought, as wells as some criticisms about Huizinga and The Autumn of the Middle Age. Specific analysis are made on some

1 Masterando en Historia de las Américas, Master en Recursos Humanos y licenciado en Psicología, ha sido docente e investigador en las universidades venezolanas UNA y UCAB. Correo electrónico: rdoperez58@gmail.com. Fecha de recepción del artículo: 13 de septiembre de 2016. Fecha de aceptación: 17 de octubre de 2016.

$\overline{\text { STVDIVM. Revista de Humanidades, } 22 \text { (2016) ISSN: 1137-8417, pp. 37-60 }}$ 
relevant themes exposed by Huizinga in his book, like the medieval chivalry, gallant love, the death or the symbolic thought logics as examples where his thinking about cultural history is showed. The present relevance of the heuristics and hermeneutics approachs proposed by Huizinga is discussed.

Key words: Huizinga, historiography, cultural history, Middle Age

\section{INTRODUCCIÓN}

El otoño de la Edad Media y su autor, el historiador holandés Johan Huizinga (1872-1945), nos devuelven al difícil e irritante problema del vínculo que los elementos culturales mantienen entre sí y, a su vez, de su relación con los elementos no culturales en el estudio de la historia, tal y como ya advirtiese Fernand Braudel, aún después de alabar la obra maestra por excelencia del neerlandés:

Lo que más le reprocho a Johan Huizinga es haber mantenido los ojos tan elevados que sólo consideró obstinadamente la última planta del espectáculo, lo alto de la hoguera. Qué lástima que no haya tenido a su disposición esos estudios demográficos y económicos, hoy clásicos, sobre el importante retroceso que sufrió Occidente en el siglo XV, pues le habrían proporcionado la base de la que su libro carece. Pues, conviene repetirlo, los grandes sentimientos, los más elevados y los más bajos por lo demás, nunca tienen una vida plenamente independiente. $^{2}$

Pero como sostenía el propio Huizinga, para comprender la vida de la cultura, tiene el valor de una verdad la ilusión en que los contemporáneos viven. Congruentemente con su vocación artística, pensaba que el oficio del historiador es un poco como el del pintor: reflejar con sus pinceladas en un cuadro algo que despertase la curiosidad de quien lo observa - de quien lo lee, en el caso del trabajo histórico- para luego ir llevando al lector de la mano a lo largo de todo el discurso histórico de tal manera que se centrara en los aspectos realmente importantes del objeto de estudio. A Huizinga le interesaban los valores lírico-asociativos del lenguaje, le asombraba cómo un mismo término era usado para significar ideas distintas a la que le había dado origen, y cómo esta generalización era asimismo compartida por otras lenguas, aunque la expresión fonética del término fuese

2 Fernand Braudel, Las ambiciones de la historia, Barcelona, Crítica, 2002, cap. VII, «Historia de las civilizaciones: el pasado explica el presente», p. 229. Este capítulo aparece originalmente en L'Encyclopedie francaise, tomo XX, cap. V, París, Larousse, 1959. 
diferente. La conclusión que sacaba Huizinga de este fenómeno es que subyacía una especie de psicología colectiva que atravesaba distintas lenguas y, por ende, distintas culturas, y que además podía mantenerse casi incólume aun con el paso del tiempo. En ese viaje co-construido entre el historiador y el lector está el verdadero reto puesto que, como él mismo decía, tanto en la realidad histórica como en la pintura hay simultáneamente varias verdades pues todo depende de la luminosidad bajo la cual la observemos.

Johan Huizinga está considerado entre los más importantes historiadores por su particular modo de entender y estudiar la historia desde el prisma de sus manifestaciones artísticas y culturales. Sin embargo, a pesar de que ya era para 1919 - fecha de la publicación en holandés de El otoño de la Edad Media-, un reputado historiador, profesor universitario y miembro de la Academia de Ciencias de Holanda, su libro tuvo una acogida dispar. Alabado inmediatamente por algunos como obra pionera no sólo en el área de la historia cultural sino dentro de la teoría de la historia por sus novedosos planteamientos epistemológicos, otros estudiosos ${ }^{3}$ como los historiadores franceses de los Annales ni siquiera lo reseñarían en su revista del 1932, cuando vio la luz la edición francesa. Aunque la obra de Huizinga puede considerarse un preámbulo al esfuerzo que hicieron Lucien Febvre, Marc Bloch y Ferdinand Braudel en sus propuestas acerca de nuevas temáticas y focos de estudio histórico - concretamente en lo referente al renovado estudio de la Edad Media, de la vida cotidiana y de la historia de las mentalidades ${ }^{4}$ - los annalistes desconfiaban de tanta literatura, filosofía y psicología y de tan poca economía y sociología como veían en la obra del holandés. Hubo que esperar a Jacques Le Goff para que la obra de Huizinga fuera plenamente reconocida por los historiadores franceses:

El Otoño aparece como un pionero y un antecesor de los nuevos campos de la historia: historia del cuerpo, historia de los sentidos, historia de los sueños y de lo imaginario [...] En sus obras, Huizinga anuncia y ayuda al nacimiento de una historia de la sensibilidad y de las mentalidades, de la vida cotidiana, y recurre a los documentos literarios y artísticos, deseando abolir las barreras que

3 Cf. Juan Miguel Valero Moreno, «Johan Huizinga. Ver la historia». I Congreso Internacional de la Sociedad de Estudios Medievales y Renacentistas, Javier San José Lera (coord.), Francisco Javier Burguillo y Laura Mier (eds.), Salamanca, Seminario de Estudios Medievales y Renacentistas, 2008, pp. 439-457.

4 Alicia Alted Vigil, «Historia de la cultura», en Blas Casado Quintanilla (coord.), Tendencias historiográficas actuales. Madrid, Universidad Nacional de Educación a Distancia, 2004, pp. 321-330.

STVDIVM. Revista de Humanidades, 22 (2016) ISSN: 1137-8417, pp. 37-60 
separan la historia de la psicología (esencialmente, la psicología colectiva), la etnología y la sociología, así como la filosofía. ${ }^{5}$

Tampoco El otoño de la Edad Media comenzó con buen pie. Las traducciones que se hicieron al francés y al inglés cambiaron su título y se publicaron como Le déclin du Moyen Age y The waning of the Middle Ages, como si lo que Huizinga quisiese estudiar fuera una época de decaimiento y ocaso cuando era, precisamente, lo contrario. Si algo quería exponer era que la última Edad Media en modo alguno fue un tiempo irrelevante y que aquello que se evaluaba como ridículo o desfasado, en comparación con el idealizado Renacimiento que le seguiría, no era sino un error de apreciación histórica. A Huizinga le interesaba mostrar, no los síntomas premonitorios y preparatorios de la llegada del Renacimiento, sino los elementos que se extinguirán al haber alcanzado su máximo esplendor, que estaban muriendo de éxito:

Seguir el declinar de las formas sobremaduras de la cultura anterior no es de menor entidad que observar el nacimiento de las nuevas [...] no considerándolos como iniciadores y heraldos de lo venidero, sino como la expresión acabada del inmediato pretérito. ${ }^{6}$

Hasta el último cuarto del siglo Xx, los trabajos de Huizinga no vuelven a ser valorados, casi como si se tratasen de obras precursoras. A continuación, trataremos de analizar específicamente dichos enfoques precursores en el que fue su trabajo histórico por excelencia: El otoño de la Edad Media.

\section{Huizinga}

Los intereses vocacionales de Huizinga estuvieron desde muy joven orientados hacia el mundo de las artes y de las letras. Imbuido por los aires en boga del orientalismo, comenzó sus estudios universitarios especializándose en lenguas antiguas, concretamente en sánscrito, si bien que también estudió árabe, gaélico antiguo, lituano, alemán y, por supuesto, letras ho-

5 Jacques Le Goff, «Johan Huizinga», en André Burguière, dir., Diccionario de ciencias históricas, Madrid, Akal, 1991, p. 350, citado por Andrés Freijomil, «Un historiador del ocaso. Los derroteros intelectuales del primer Huizinga (1897-1919)», Prismas,13/1, 2009, disponible en http://www.scielo.org.ar.

6 Johan Huizinga, El otoño de la Edad Media. Madrid, Alianza Universidad, 1982 (4. ${ }^{\text {a }}$ edición), p. 11.

STVDIVM. Revista de Humanidades, 22 (2016) ISSN: 1137-8417, pp. 37-60 
landesas. Sus estudios le llevaron a familiarizarse con culturas y tiempos antiguos, como el de las vedas hindúes y las sagas normandas. Dados sus intereses y conocimientos literarios y artísticos, resulta comprensible que los utilizara en sus investigaciones históricas. En este sentido, diría que le parecía un error de parte de los historiadores menospreciar el arte y las letras como fuente valiosa de conocimiento histórico y tratar de circunscribirlos al área específica, aislada, de la historia del arte o la historia de la literatura. Huizinga pensaba que las manifestaciones artísticas podían ser tan valiosas como los documentos oficiales, los discursos políticos o las estadísticas económicas a la hora de indagar sobre el pasado de cualquier sociedad.

De espíritu libre y tolerante, como buen enamorado del arte que era, Huizinga nunca compartió esquemas deterministas en el análisis de la historia. Así, se opondrá a los positivistas, negando que la historia pudiera estudiarse como si fuera una ciencia natural más; también a los historicistas, pues no compartía la visión de que la historia tuviera que responder a algún fin específico; y a los marxistas, ya que consideraba un sinsentido reducir la historia a una simple consecuencia automática de las relaciones sociales y económicas. Huizinga no despreciaba la historia política pero tampoco creía que ésta fuese el motor principal del devenir histórico. En este punto, su visión se encontraba en el polo opuesto de la historiografía whig británica de la segunda mitad del siglo XIX que primaba la historia política y la epistemología empirista. ${ }^{7}$ No despreciaba la historia intelectual pero consideraba que ésta no podía limitarse al estudio de las ideas racionales y sostenía que debía incluir también el estudio de otros tipos de pensamientos y sentimientos, en algo más parecido a lo que podría denominarse como historia espiritual o de las sensibilidades.

Huizinga se rebelaba contra las posiciones extremas y absolutas. Por ejemplo, consideraba un error pensar que los cambios históricos se producían abruptamente o que las características de un tiempo o sociedad específicos se daban de manera uniforme en todos sus grupos sociales y territorios, entre un mismo grupo social o incluso en una misma persona. El veía en lo que hoy denominaríamos 'diversidad' o incluso 'bipolaridad', una valiosa oportunidad para el estudio histórico. Esta relatividad la apli-

7 Jaume Aurell y Peter Burke, «El siglo de la historia: historicismo, romanticismo y positivismo", en Jaume Aurell, Catalina Balmaceda, Peter Burke y Felipe Soza, Comprender el pasado. Una historia de la escritura y el pensamiento histórico, Madrid, Akal, 2013, pp. 199-235. 
caba al uso de las fuentes, señalando que las variables bajo estudio no se expresan de la misma manera en todas las fuentes, por lo que el historiador tiene que entender primero cómo se comporta cada fuente y qué características se pueden observar mejor en una fuente que en otra.

Huizinga era un fiel representante del momentum historiográfico del denominado periodo de entreguerras (1918-1939), caracterizado por un retorno al hombre como objeto central del conocimiento histórico, del abordaje contextual de los problemas, de la multidisciplinariedad en el enfoque. ${ }^{8}$ No entendía la historia como una simple acumulación de descubrimientos mediante una reconstrucción objetiva y literal del pasado. Los historiógrafos refieren que la aproximación de Huizinga a la historia cultural estaba aún relacionada con la de historiadores de la anterior generación —como el suizo Jacob Buckhardt y el alemán Karl Lamprecht—, por lo que le ubican dentro de la denominada «escuela clásica» de la historia cultural. ${ }^{9}$ En efecto, Huizinga es heredero historiográfico de Buckhardt en la medida en que fue éste quien primero rompió con la visión tradicional que se tenía del arte y de la cultura como objetos de estudio del historiador. ${ }^{10}$ Lo fue también de Lamprecht, en la medida en que fue gran impulsor de la idea de que el historiador debía recurrir a enfoques multidisciplinarios en vez de encerrarse en su propia torre de marfil. Y fue precisamente por esto por lo que El otoño de la Edad Media tuvo tanto éxito fuera del claustro universitario academicista y entre otros ambientes cultos no necesariamente integrados por historiadores.

Las críticas más frecuentemente vertidas por diversos historiadores tienen que ver con el enfoque epistemológico de Huizinga, tanto en lo referente a su heurística — donde las manifestaciones artísticas son fuentes válidas para comprender una sociedad-como, sobre todo, por su particular hermenéutica llena de simbolismos, interpretaciones e intuiciones. Sostenía con cierta lógica que el arte verdadero es el mejor indicador de la libertad humana, pues sólo se puede dar cuando se han satisfecho las

8 Jaume Aurell y Peter Burke, «De entresiglos a la década de los setenta: la reacción frente al positivismo", en Jaume Aurell, Catalina Balmaceda, Peter Burke y Felipe Soza, Comprender el pasado... 2013, pp. 237-285.

9 Carlos Martínez Shaw, «Historia moderna», en Blas Casado Quintanilla (coord.), Tendencias historiográficas..., 2004, pp. 233-284.

10 Jaume Aurell y Peter Burke, «El siglo de la historia: historicismo, romanticismo y positivismo", en Jaume Aurell, Catalina Balmaceda, Peter Burke y Felipe Soza, Comprender el pasado..., 2013, pp. 199-235. 
necesidades apremiantes de la vida diaria. En la lucha diaria por llevarse el pan a la boca - en el caso de los vasallos y las clases populares- o en la lucha política y jurídica por derrotar a tal o cual enemigo político - en el caso de monarcas y señores feudales - la mente del hombre no es libre, pues está ocupada en alcanzar un objetivo específico y dispuesta a sacrificar lo que sea en este camino, incluidos la verdad y sus más genuinos sentimientos. Por el contrario, en el tiempo dedicado al goce, al esparcimiento, al divertimento y al disfrute del arte, de la belleza, de la alegría y de la amistad, es donde más libertad puede expresar el ser humano por encontrarse libre de presiones de otro tipo: su única presión será el grado de satisfacción, que en el caso de las manifestaciones artísticas se traduce en el grado de belleza que alcance. Así, el análisis de lo estético pasa a ser una elección para el historiador, pues a través de las manifestaciones artísticas se reflejan más genuinamente los valores, actitudes y percepciones que tienen las gentes sobre la vida y su sociedad y que el artista, pintor o poeta se encargará de traducir y expresar en el lenguaje de la estética. ${ }^{11}$

Otra crítica, muy asociada con El otoño de la Edad Media, está basada en la atención mayoritaria que Huizinga presta a la vida de las clases altas - monarcas, eclesiásticos, señores feudales y caballeros- en detrimento de las clases populares, por lo que la visión que ofrece el holandés sobre la vida bajomedieval está realmente limitada a la vida de dichas élites y altos estamentos. Pero Huizinga no compartía la tesis de que la vida de las élites poderosas estaba separada y no tenía nada que ver con la vida del resto de su sociedad y de su tiempo. Por el contrario, sostenía que en las obras de arte y de literatura que los pintores, cronistas y poetas producían para sus monarcas, señores feudales y autoridades eclesiásticas, es donde mejor se reflejan los valores y actitudes de la sociedad, incluyendo los de burgueses, comerciantes, artesanos, siervos, campesinos y vasallos en general. Bien sea que estos artistas y literatos realizaban su labor de manera autónoma para alabar a sus señores, o bien sea porque lo hacían a petición expresa de éstos para publicitar sus éxitos y grandezas y para criticar y desprestigiar a sus adversarios políticos, el camino estético que escogía el artista tenía obligatoriamente que estar conectado con el sentir mayoritario de toda la sociedad, pues si no fuere así, ¿cómo iba a tener éxito en su función de proclama?

11 Este enfoque no apareció por vez primera en El otoño de la Edad Media pues ya en 1905, la lectura inaugural de Huizinga en la cátedra universitaria en Groninga lleva el título de «El elemento estético de las representaciones históricas». 
La vida seguía ostentando en más de un respecto el color de la leyenda. Si los cronistas de la corte, varones distinguidos y eruditos, que conocían de cerca a sus príncipes, no aciertan a ver ni a describir a aquellas serenísimas personas de otro modo que en una forma arcaica, hierática, cuán grande tiene que haber sido el mágico brillo de la realeza para la ingenua fantasía popular. (Huizinga 1982: 22)

Así, para Huizinga el estudio de las vidas de las élites y de los poderosos es un camino válido para llegar a la comprensión de todo el conjunto social, incluida la comprensión de los valores y creencias de las clases populares, y afirmaba con contundencia que la historia de la cultura debe interesarse tanto por los sueños de belleza y por la ilusión de una vida noble, como por las cifras de población y de tributación. Nuestro historiador holandés no proponía que esta vía heurística y hermenéutica fuese la única, como tampoco había llegado aún el tiempo historiográfico de la antropología, el marxismo inglés, los estudios culturales británicos, el postestructuralismo filosófico o sociológico, los estudios de género y la microhistoria, corrientes todas éstas de pensamiento que aparecieron después de la muerte de Huizinga y que dieron un nuevo empuje y foco tanto a la historia social, ahora sí con la incorporación masiva y diferenciada en ella de las expresiones culturales de las clases populares. ${ }^{12}$

Otros análisis sobre El otoño de la Edad Media tienen que ver con sus interpretaciones acerca de algunas realidades de la época, concretamente y sobre todo, con el llamado espíritu caballeresco. Para Huizinga, el espíritu caballeresco no era algo específico a un determinado grupo social, sino que impregnaba la vida de todos los grupos sociales de la época, pues se conformaba como un elemento identitario de la misma. Esto no significa que todos los grupos expresasen esta impregnación de la misma manera, pero sí compartían su espíritu, su imaginario, bien fuese para laudarlo o para satirizarlo. Huizinga está tan convencido de esta fortaleza del espíritu caballeresco bajomedieval que apunta una atrevida hipótesis histórica según la cual dicho espíritu aún se encontraba presente — si bien transmutado en sus formas - en la cultura, valores y formas deseadas de vida de la pujante burguesía de finales del siglo XIX y principios del XX. El holandés advierte del peligro de quedarse con la imagen fatua, desfasada y ridícula que de las manifestaciones caballerescas del siglo XIV se tiene pues debajo de estas

12 Jorge Myers, «Historia cultural», en Carlos Altamirano (dir.), Términos críticos de sociología de la cultura, Buenos Aires, Paidós, 2002, p. 127, citado por Andrés Freijomil, «Un historiador del ocaso...», 2009, p. 56. 
formas «superadas» se encuentran unos valores y actitudes hacia la vida muy asentados, que venían de muy lejos y que permanecieron en el tiempo:

El hombre moderno no se hace, por lo regular, idea de la desenfrenada extravagancia e inflamabilidad del espíritu medieval. Quien sólo buscase información en los documentos oficiales, considerados con justicia como las fuentes más seguras para el conocimiento de la historia, podría hacerse de este trozo de la historia medieval una imagen [...] Pero en semejante imagen faltaría un elemento importante: el colorido chillón de la pasión violenta que animaba tanto a los pueblos como a los príncipes. (Huizinga, 1982: 28)

\section{El ESTILO NARRATIVO COMO CLAVE DEL DISCURSO HISTÓRICO}

En cierta manera, El otoño de la Edad Media es un excelente medio para aproximarse a la historiografía medieval y a la manera en cómo los cronistas e historiadores de aquella época veían y entendían su tiempo. Huizinga recoge sus vestigios bajomedievales y protorrenacentistas de un grupo de fuentes escritas por cronistas, literatos, canónigos y cortesanos que vivieron en el propio contexto espacio-temporal de estudio, para construir sobre esta base un novedoso relato en donde los factores estéticos y poéticos de la narración ocupan un lugar clave, pero sin desatender la rigurosidad epistemológica. Sin descuidar el recurso a la erudición documental tan típica de la historiografía positivista, Huizinga rehabilita y defiende el uso de otro tipo de fuentes aún desacreditadas por la nueva historiografía académica y profesional que surgió en el siglo XIX:

La vida diaria ofrecía de continuo ilimitado espacio para un ardoroso apasionamiento y una fantasía pueril. Nuestras investigaciones históricas, que prefieren beber todo lo posible en los documentos oficiales, por desconfianza hacia las crónicas, incurren por ello muchas veces en un peligroso error. Los documentos nos dan escasa noticia de la diferencia en el tono de la vida que nos separa de aquellos tiempos, y nos hacen olvidar el vehemente pathos de la vida medieval. De todas las pasiones que la colman de color, por lo regular, mencionan sólo dos: la codicia y la belicosidad [...] Para comprender con justeza aquellos tiempos son, pues, indispensables los cronistas, por superficiales que puedan ser y por frecuentemente que yerren en lo tocante a los hechos. (Huizinga, 1982: 21-22)

Se trataba de una historiografía que había experimentado cambios significativos a principios del siglo XIII, y que se caracteriza por una mayor secularización y vernacularización tanto de los historiadores como de los contenidos, por ser más testimonial que compiladora en su enfoque y por 
un estilo narrativo más espontáneo y dramático; ${ }^{13}$ en pocas palabras, la historia se convierte en el relato en prosa de los hechos brillantes de los que da fe. ${ }^{14}$

Decir que el apasionamiento descriptivo de Huizinga con el que busca sensibilizar al lector sobre el tono de la vida cotidiana y los anhelos del hombre de la última Edad Media se observa en la simple lectura del texto, sería quedarse cortos y no transmitir fielmente el contenido. Hay que decir, más bien, que la pasión brota como un torrente de su narrativa, como si el historiador holandés no pudiera contener el tempestuoso mar de sensibilidades que le produce la época que investiga y estudia. Este tono constituirá una característica estilística en toda su producción historiográfica por la que fue tanto alabado como criticado:

Tan abigarrado y chillón era el colorido de la vida, que era compatible el olor de la sangre con el de las rosas. El pueblo oscila, como un gigante con cabeza de niño, entre angustias infernales y el más infantil regocijo, entre la dureza más cruel y una emoción sollozante [...] En las amenazadoras advertencias de los predicadores, en el cansado suspirar de la alta literatura, en la monótona información de las crónicas y de los documentos, se percibe el grito de los pecados saturados de color y el lamento de la miseria. (Huizinga, 1982: 39)

Esta estilística narrativa puede llevarnos a pensar que Huizinga era un historiador romántico. Ciertamente, compartiría con Jules Michelet, el gran historiador romántico francés del siglo XIX, la idea de que la visión poética y artística son instrumentos también de conocimiento y no únicamente la ciencia y el raciocinio; la convicción de que los grandes protagonistas de la historia son los símbolos y éstos encarnan ideas; y la certeza de que la historia no es más que manifestación del espíritu del mundo. ${ }^{15}$ Pero lo que Huizinga no compartiría en absoluto con Michelet y los románticos sería su desenfrenado ímpetu nacionalista que buscaba en la historia las raíces de la nación y de su pueblo. En El otoño de la Edad Media no encontrará el lector ninguna señal ni referencia al orgullo nacional neerlandés y todas las fuentes medievales presentadas en la obra lo son para ayudar a

13 Jaume Aurell, «La historiografía medieval: siglos IX al XV», en Jaume Aurell, Catalina Balmaceda, Peter Burke y Felipe Soza, Comprender el pasado..., 2013, pp. 94-142.

14 Charles-Olivier Carbonell, La historiografía. México, Fondo de Cultura Económica, 1986.

15 Jaume Aurell y Peter Burke, «El siglo de la historia: historicismo, romanticismo y positivismo", en Jaume Aurell, Catalina Balmaceda, Peter Burke y Felipe Soza, Comprender el pasado..., 2013, pp. 199-235. 
que el lector comprenda un tiempo en un país, y no al revés. Por último, mientras los historiadores románticos miraban con nostalgia al pasado, con sentimiento de pérdida de una especie de paraíso perdido, Huizinga estudia una época pasada con alegría, entusiasmándose al descubrir cuántas cosas de las que vivimos hoy en día provienen de ella.

Por más negra que puede ser una época, siempre existen aspectos positivos y de felicidad en ella que pueden ser ignorados por los historiadores en su afán por destacar lo novedoso y mejor de la época nueva que le sigue, como fue en este caso el Renacimiento. Desde esta perspectiva, puede afirmarse que El otoño de la Edad Media estaba más próximo de aquellos filósofos de la historia e historiadores que propugnaban que el sujeto de la historia es, como sostenía Ortega y Gasset, la dimensión vital y circunstancial del hombre. No en vano, Ortega había alabado de inmediato la aparición de la obra de Huizinga.

Desde esta óptica vitalista y como respuesta a las vicisitudes que las circunstancias de la última Edad Media le ofrecían, Huizinga plantea que el hombre bajomedieval sólo tenía tres actitudes distintas ante la posibilidad de alcanzar una vida mejor: a) negar esta posibilidad, pues la única vida mejor es la del más allá después de la resurrección, b) el mejoramiento y perfeccionamiento del mundo y, c) la ensoñación. Estas tres actitudes espirituales producen efectos diferentes sobre la vida real. Su hipótesis es que la tercera de estas actitudes, la ensoñación, fue la que predominó en la última Edad Media y que se manifiesta en la exacerbación de la conversión de las formas de la vida en formas artísticas, razón por la cual es el arte una fuente idónea para que el historiador estudie y alcance la comprensión global de la época. La aplicación de criterios esteticistas en las formas de la vida se revelaba hasta en los aspectos de la vida diaria. Persistentemente, advierte que todas estas formas estéticas pasaron sin dejar huella directa en las llamadas artes y literaturas cultas, por lo que una historia cultural, artística o intelectual al modo tradicional no las revelará.

En El otoño de la Edad Media el historiador holandés centra su estudio alrededor de ejes temáticos o contenidos que él considera paradigmáticos de la última Edad Media - el espíritu caballeresco, el amor cortés y la imagen de la muerte y la expresión de la religiosidad-, y los estudia mediante un análisis simbólico de las crónicas y escritos históricos de la época, con la ayuda muchas veces de la etnología y de sus amplios conocimientos sobre lenguas y civilizaciones antiguas. Pero se aventura más allá y desentraña en sus fuentes dos categorías de análisis no fácilmente observables a primera vista, o al menos no desde la lectura del historiador convencional 
de documentos y archivos: el pensamiento simbólico bajomedieval y el arte como expresión vital, categorías a las que supone una lógica intrínseca de funcionamiento que es necesario comprender para poder estudiar acertadamente la época.

\section{El ESPÍRITU CABALLERESCo}

El tratamiento que Huizinga da al fenómeno de las órdenes de caballería en la última Edad Media era muy diferente del que se observa en otros historiadores de su tiempo, sobre todo los encuadrados en la escuela historicista. Por ejemplo, George Gordon Coulton, gran medievalista inglés, escribió trabajos sobre las órdenes caballerescas, la vida en los poblados campesinos medievales, sobre historia eclesiástica medieval e incluso sobre historia del arte, pero con un enfoque eminentemente basado en documentos, como era más característico en los historicistas, tal cual se puede observar en su A medieval garner: buman documents from the four centuries preceding the reformation, obra publicada en 1910. Otro importante medievalista contemporáneo de Huizinga, el francés Charles Langlois, estudiaba sus objetos de investigación buscando explicaciones basadas en el poder político y la administración de las instituciones de la época, como se puede leer en su obra Le regne de Philippe III, le Hardi, basada en hechos de finales del siglo XIII y publicada en 1887 . Y otro destacado medievalista, el belga Henri Pirenne, elaborará su célebre trabajo sobre las ciudades medievales publicado en 1925, con un enfoque centrado en lo social y lo económico.

Los intereses de Huizinga sobre las órdenes caballerescas irán por otros derroteros. Este expreso interés en lo que un determinado objeto de estudio histórico —en este caso los votos caballerescos—, significa para las personas y no lo que significa desde, por ejemplo, una óptica política o militar, representa bastante fielmente los nuevos aires de la historiografía de entreguerras como reacción al historicismo más clásico y al positivismo más racionalista.

La tesis de Huizinga es que el ideal caballeresco cumplía en la última Edad Media una función estética que se enlazaba con una función ética en cuanto que ponía al caballero como protector de los débiles, pero bajo ningún respecto debe deducirse que hubiese en esto mayor asomo de reforma social. El ideal caballeresco inicial, antiguo, es ascético, compasivo, fiel, justo, casi monástico. El ascetismo caballeresco, en su denodada abnegación, es tan sólo la traducción moral de un deseo vital insatisfecho al cual 
hay que buscarle experiencias de vida — que siempre serán experiencias formales pomposas y regladas, acordes al espíritu de la ensoñación de la época- en las que desplegarse, experiencias como el trato cortés, los juegos de sociedad, las diversiones y los torneos y deportes:

La última Edad Media es uno de esos periodos terminales, en que la vida cultural de los altos círculos sociales se ha convertido casi íntegramente en un juego de sociedad. La realidad es áspera, dura y cruel; por ende, se la somete al bello sueño del ideal caballeresco y se edifica sobre éste el juego de la vida [...] reina una enorme insinceridad consigo mismo cuya detonante falsedad solo puede ser soportada gracias a que hay una leve ironía que salpica la mentira dicha a sí propio. En toda la cultura caballeresca del siglo XV impera un equilibrio inestable entre la gravedad sentimental y una ligera ironía [...] De cuando en cuando hay un momento en que la risa descompone el gesto rígido. (Huizinga, 1982: 111)

En línea con su tesis, Huizinga sostiene que para entender las órdenes militares medievales no basta con recurrir a explicaciones basadas en la política o en la religión, pues muchos de sus símbolos y procedimientos estatutarios y organizativos se retrotraen a primitivas y sagradas tradiciones hindúes, judaicas y normandas. Sostiene que los relatos de estos tiempos que nos parecen exagerados, no lo son si los analizamos con la ayuda de la etnología.

Nuestro historiador holandés busca indagar el efecto de estas formas nobles en la vida de los siglos XIV y XV. Puede decirse que las ideas caballerescas no tuvieron repercusión en las excelencias de esta época, pero sí en sus errores, puesto que cuanto más imbuido está un ideal por la aspiración a las más altas virtudes, mayor es la discrepancia con la realidad, hasta que al final la contradicción se vuelve tan ostensible que no se puede sostener y no le queda otro remedio que transformarse, para lo cual cae siempre la cáscara, la mentira:

La mentira (...) se refugia más y más en la esfera de las letras, las fiestas y los juegos. Sólo allí podía mantenerse la ilusión de la bella vida caballeresca. Allí se está entre los miembros de la casta para la cual única y exclusivamente tienen valor todos esos sentimientos. Es asombroso como fracasa la caballerosidad en el acto mismo en que hacerse valer frente a los no valorados como iguales. Tratándose de las clases inferiores, falta toda necesidad de elevación caballeresca. (Huizinga, 1982: 147)

La forma caballeresca de vida había llegado ya a un punto de hastío en el que hasta la misma nobleza sentía desagrado por ella: era superflua y se sabía que era un anacronismo. Una forma de huir de este anacronismo era 
la alegoría por la vida idílica, pastoral, sencilla, bucólica, sin convencionalismos, que reúne cierto grado de belleza naturalista también y es menos ruda que la vida real, razón por la cual, según Huizinga, proliferaron tanto en esta época las églogas como forma literaria. Por ello consideraba que los historiadores de este periodo debían estudiar este género literario.

\section{EL AMOR CORTÉS}

$\mathrm{El}$ amor, el miedo y otros sentimientos, emociones y experiencias íntimas humanas comenzaron a estudiarse de manera más sistemática con el auge de la historia social y con la aparición de la llamada historia de las mentalidades. Los primeros enfoques en la historia del amor partieron del mundo de la historia social y estuvieron referidos a la historia de la familia y de la infancia, con una cierta intención de reivindicación de grupos sociales discriminados o minimizados como la mujer y el niño. Sólo en una segunda etapa comenzaron a aparecer estudios sobre el amor como experiencia conyugal y erótica, pero por lo general también desde una perspectiva social que tendía a presentar las diferencias entre distintos grupos sociales. Pero de nuevo, los intereses de Huizinga van por otro lado y, lejos de buscar diferencias entre colectivos sociales, lo que pretende es mostrar cómo un espíritu específico - el caballeresco-invadía y permeaba a todas las personas de una u otra manera, incluso en algo tan íntimo y humano como el amor.

El espíritu caballeresco se refleja también en el amor del caballero por su dama, amor que es siempre y continuamente sublimado, convirtiéndose dicho caballero en un héroe que sacrifica sus pasiones en aras de su amor. Es el deseo del ser humano que sufre pero que acepta este sufrimiento porque está también dispuesto a sufrir por liberar a su dama. Huizinga hace aparecer este esquema motivacional casi como arquetípico, resurgiendo y manteniéndose en todas las sociedades con distintas vestimentas, inclusive en la sociedad actual, porque su tesis es que se trata de un elemento propio de la naturaleza y de la vida misma, en lo que es otra de las tantas argumentaciones etnológicas de su gusto:

La sociedad medieval ha cultivado este motivo romántico-primitivo con una insaciabilidad juvenil. Mientras que las formas superiores de la literatura se han refinado dando al deseo una expresión más etérea y reservada o más ingeniosa y picante, renuévase la novela de caballerías una y otra vez, conservando en medio de su refundición del caso romántico, repetida sin fin, un incentivo que no siempre nos resulta comprensible. Nos parece que aquellos tiempos eran ya demasiado crecidos para complacerse en tan infantiles fanta-

STVDIVM. Revista de Humanidades, 22 (2016) ISSN: 1137-8417, pp. 37-60 
sías [...] Pero no lo eran, como tampoco lo es hoy el folletín. Solo que nada de ello es pura literatura sino [...] artes aplicadas. Es la necesidad de modelos para la fantasía erótica la que mantiene viva y renueva siempre esta literatura. (Huizinga, 1982: 110)

Los folletinistas de hoy, como los trovadores de ayer, convierten la insatisfacción amorosa en la protagonista de sus cantos. El otoño de la Edad Media considera una equivocación que el historiador se contente con señalar como hipócritas, gazmoñas, impúdicas y decadentes todas estas prácticas amorosas cortesanas y caballerescas, prácticas que, por el contrario, tienen que ser estudiadas como restos de un simbolismo fálico primitivo que ha sido atenuado con el paso del tiempo y convertido en formas de trato social. ${ }^{16}$

El género literario cómico-erótico frecuente en la última Edad Media sería una muestra cultural derivada del argumento recién descrito, que fue tomando autonomía propia. Los oficios, los juegos y hasta cierta liturgia religiosa son considerados por Huizinga como reflejo de este estilo epitalámico del amor que fue transferido a otras esferas de la vida cotidiana. Es una especie de torneo entre la erótica inmediata epitalámica y la erótica mediata sublimada en el cual los dolores del amor se transforman en un valor vital superior como es la belleza, de índole más general y que puede ser extrapolado a otras facetas de la vida. Este tipo de interpretaciones - $\mathrm{O}$ de intuiciones como las llamaba Huizinga-, eran las que tanto asustaban a los colegas historiadores...

\section{LA IMAGEN DE LA MUERTE Y LA EXPRESIÓN DE LA RELIGIOSIDAD}

La vida espiritual de la última Edad Media se caracterizaba por la necesidad ilimitada de prestar forma plástica a todo lo santo, lo que acabará promoviendo una gran superficialidad en la expresión religiosa, petrificando el objeto de la misma, banalizándolo. Pululaban invenciones religiosas que parecían más bien supersticiones, incrementándose el culto popular a sus imágenes y, en general, la vida entera estaba tan empapada

16 Si no fuera porque las fuentes consultadas reportan que Huizinga era un crítico del psicoanálisis, podríamos pensar que el razonamiento del neerlandés había sido extraído de Totem y tabú, de Sigmund Freud, publicado apenas seis años antes, o incluso aventurar que Carl Jung copió párrafos enteros de El otoño de la Edad Media en sus obras aparecidas unos pocos años después, sobre el inconsciente colectivo y los arquetipos.

STVDIVM. Revista de Humanidades, 22 (2016) ISSN: 1137-8417, pp. 37-60 
en religión que amenazaba borrarse a cada momento la distancia entre lo sagrado y lo profano. Huizinga advierte nuevamente a los historiadores de caer en el error de considerar este sobre-expresionismo religioso entre fastuoso y mundano como mera degradación de la época, sin mayor interés histórico:

El pueblo pasaba sus días en la rutina de una religión que se había tornado completamente superficial. Poseía una fe muy firme, que traía consigo temores y éxtasis: pero esta fe no sumía al iletrado en discusiones ni luchas espirituales, como había de hacer más tarde el protestantismo. La indiferente familiaridad y llaneza de la vida cotidiana alternaba con espasmos de la más entrañable emoción religiosa (...) No se puede comprender el contraste continuo entre la tensión y la laxitud religiosa, dividiendo, por ejemplo, a la grey religiosa en personas piadosas y entregadas a la vida mundanal como si una parte del pueblo hubiese vivido continuamente con severa religiosidad, mientras los demás sólo fueran superficialmente religiosos. (Huizinga, 1982: 249)

Pero aún en este sentido, y fiel a su actitud anti-determinista y antiuniformizadora, Huizinga señala que hay, por ejemplo, diferencias regionales entre el norte y el sur de Flandes, donde se dan diferentes formas de expresión religiosa. Huizinga extrapola su argumento inicial a otro de alcance más amplio y de tipo etnológico basado en las diferentes maneras en las que, a su entender, nórdicos y latinos afrontan las contradicciones y conflictos entre religiosidad y la vida cotidiana. El otoño de la Edad Media explica también las diferencias existentes entre el alto clero y el bajo clero, las formas de vida que llevaban los eclesiásticos y el modo en que el pueblo llano las percibía y criticaba. Las contradicciones que se dan en la religiosidad de las clases populares se dan también entre los religiosos, los nobles y los poderosos, por el mismo lastre de prolija pomposidad y de inmoderada sensualidad. Pero esta contradicción no se vive como hipocresía ni para tapar una cosa con la otra ni en secretismo, que es lo importante de entender de esta época. Para Huizinga se trata de una tensión entre dos polos espirituales de un mismo y único continuum que no se comprende en el mundo moderno.

\section{El PENSAMiento Simbólico Bajomedieval}

Huizinga expone su teoría sobre la comprensión del simbolismo y cómo abordarlo como objeto del estudio histórico, dedicando varios capítulos de su obra a estos fines. No es de extrañar este interés dada su afición por la poesía y, en especial, por la obra literaria del gran maestro francés del simbolismo, Paul Verlaine. Huizinga no hace sino deleitarse con una época plaga- 
da de simbolismo y de una estética rebosante, farragosa, recargada, de la que el estilo gótico florido con sus espléndidas catedrales es digno ejemplo:

La exagerada fe de aquel tiempo quería traducirse siempre y directamente en fogosas y plásticas imágenes sensibles. El espíritu creía haber comprendido el milagro tan pronto como lo veía ante sus ojos. La necesidad de adorar bajo signos visibles lo no aprehensible en palabras, creaba sin cesar nuevas palabras. (Huizinga, 1982: 286)

Huizinga compara el pensamiento racional, causal, evolutivo, con el pensamiento simbólico: mientras que el primero busca causas y efectos, el segundo se da de súbito al encontrar una conexión entre dos cosas que tiene sentido y finalidad, que se refiere a algo de valor universal. El oto$\tilde{n} o . .$. analiza el pensamiento simbólico con el apoyo de explicaciones antropológicas: el espíritu primitivo es básicamente nominalista, donde las cosas existen en cuanto que se nombran o los colores asumen la existencia de lo que supuestamente representan como símbolo. El simbolismo convierte el fenómeno en idea y la idea en imagen, de tal suerte que la idea permanece siempre infinitamente activa e inasequible en la imagen:

El exceso de representaciones a que había reducido casi todas las cosas el pensamiento medieval ya en su otoño, habría sido simplemente una desatada fantasmagoría, si cada figura, si cada imagen no hubiese tenido más o menos su puesto en el gran sistema general del pensamiento simbólico [...] Nunca se ha olvidado que sería absurda cualquier cosa, si su significación se agotase en su función inmediata y en su forma de manifestarse; nunca se ha olvidado que todas las cosas penetran un buen pedazo en el mundo del más allá. Este saber nos es familiar, como sentimiento no formulado que tenemos en todo momento [...] Esta percepción puede aparecer a veces en la forma de una obsesión morbosa, a la que las cosas le parecen preñadas de una amenazadora intención personal o de un enigma que sería indispensable conocer y, sin embargo, resulta imposible descifrar. (Huizinga, 1982: 287)

Existía en el última Edad Media una necesidad de aislar cada conocimiento y de prestarle como entidad especial una forma propia para así poder conectarlo con otros acontecimientos en asociaciones jerárquicas. Es una lógica particular y nominalista, poco racional. En la Edad Media hay una enorme tendencia a personificar las cosas inanimadas dándoles nombres: todo tenía una significación a la que se asociaban valoraciones morales en forma de parábolas, de sentencias, de textos, de refranes, de blasones heráldicos... Los orígenes del derecho también están relacionados con esta mentalidad de reglas de torneos y juegos. Es un derecho formalista, basado en la forma del acto cometido y menospreciando las intenciones. 
Para Huizinga, la historia de la cultura en cuanto historia espiritual ha de considerar con mucha seriedad esta forma de pensamiento. El último periodo de la Edad Media vive y usa toda esta simbología en exceso, como todo, hasta el punto de petrificarla por abuso de uso, perdiendo su sentido y convirtiéndose en mero hábito. El simbolismo era el órgano del pensamiento medieval, pero era al final un simbolismo mecánico, rígido, que exagera la solidez del sistema. La lógica medieval enseguida recurre al cielo, a lo divino, a la herejía, para demostrar cualquier cosa por nimia que ésta sea. Para cada forma de vida, estamento social o profesión se elabora un ideal religioso-moral por el que hay que conducirse. Pero es una teoría de los deberes que se va haciendo muy general y conceptual, que se va despegando de la realidad cotidiana del individuo para fijarse en un plano idealista generalizador que acaba volviéndose un sinsentido. Todo es una incesante explicación detallada, hay una infinita capacidad y deseo de organización que vuelve rígido el sistema intelectual.

El discurso de El otoño... se torna en este punto muy filosófico, muy especulativo. Huizinga parece describir su propia teoría sobre el simbolismo desde el punto de vista de su lógica intelectual más que desde las fuentes. No se puede decir que Huizinga hiciese historia intelectual, tal y como se suele entender ésta: no estudiaba ideologías sino sensibilidades y el intelecto le atraía como mecanismo para entender cómo se relacionaba con esas sensibilidades.

\section{LOS CAMINOS VITALES DE LAS ARTES Y SU LÓGICA INTRÍNSECA}

El arte ya había sido vislumbrado por historiadores anteriores a Huizinga como una posible fuente para el estudio de la historia, y no sólo de la historia del arte. De hecho, hasta alguien tan metodológicamente opuesto como Hipólito Taine, historiador positivista francés de la segunda mitad del siglo XIX, ya manifestaba que la obra de arte puede ser estudiada como producto del estado general del espíritu y las costumbres ambientales. ${ }^{17}$ Sin embargo, la gran diferencia con los positivistas en cuanto al

17 Jaume Aurell y Peter Burke, «El siglo de la historia: historicismo, romanticismo y positivismo", en Jaume Aurell, Catalina Balmaceda, Peter Burke y Felipe Soza, Comprender el pasado...2013, pp. 199-235.

STVDIVM. Revista de Humanidades, 22 (2016) ISSN: 1137-8417, pp. 37-60 
estudio del arte en la historia reside en que para Huizinga el arte no sólo es un producto histórico a través del cual estudiar procesos y contextos, sino que el arte mismo es una heurística que además exige su propia hermenéutica.

La imagen que se tenía entre los intelectuales e historiadores románticos del siglo XIX sobre la última Edad Media era lúgubre, violenta, cruel, codiciosa, pomposa, vengativa. Pero cuando se recurre a las artes plásticas se tiene una imagen distinta, apacible, tranquila. Huizinga se pregunta a qué se debe esa diferencia:

¿Es característica de aquella época una fuerte desavenencia entre las varias esferas y formas de manifestarse la vida? ¿Era la esfera vital de que brotó el arte puro e íntimo de los pintores, distinta y mejor que la de los príncipes, los nobles y los literatos? ¿Pertenecen acaso aquellos (...) y la canción popular, a un pacífico limbo al margen del infierno crepitante? ¿O es un fenómeno general el de que las artes plásticas dejen detrás de sí una imagen de los tiempos más serena que la palabra de los poetas y de los historiadores? (Huizinga, 1982: 355)

En aquella época el arte no buscaba la belleza sino la vida bella. La vida artística estaba totalmente encerrada en la vida social, por eso no se puede hablar de diferencia entre el arte culto y el arte pagano. Las fiestas son un ejemplo pues constituyen la manifestación soberana de la cultura en cuanto que sirven para exteriorizar colectivamente la alegría de vivir. Las decoraciones y organización de las fiestas y de los eventos que se organizaban para recibir a los nobles en una villa eran extravagantes, pero las hacían los mismos pintores y artistas contratados para cosas más cultas o religiosas. Es diferente en el mundo contemporáneo donde el hombre individualmente puede gozar de su alegría de vivir sin necesidad de recurrir a socializar con otros. Pero no siempre fue así. En la última Edad Media aún no era así. Huizinga entiende que el admirador del arte de la actualidad no se puede comparar con el admirador del arte del siglo XV. La conciencia del disfrute estético de las artes plásticas y aún de la misma literatura ha sido desarrollada sólo muy recientemente. El admirador del arte en el Medievo no era otro que un hombre de pueblo asombrado, que desconoce el concepto de estética, por lo que cuando alguna obra artística le gusta, le asombra o le entusiasma, la interpreta casi como una especie de manifestación divina en la cual hay que creer y en la que no se hace necesario ningún tipo de análisis o estudio racional al respecto.

La pintura de la última Edad Media era vista como de mayor calidad estética que la literatura. Huizinga sostiene que esto no se debe a que los 
pintores medievales eran mejores que los literatos: se debe al imperio de la forma, que en la pintura puede evocar sensaciones estéticas, pero que en la literatura es más difícil que lo logre. Para provocar la misma reacción estética, el autor debe tener en cuenta el medio en que lo expresa, el cual requiere que el contenido sea presentado de forma acorde a éste. El artista de la última Edad Media vivía impregnado de formalismo superfluo que resulta fatal para la literatura, pues hace a ésta aburrida y sin brillo. Huizinga propone comparar pintura y literatura teniendo esto en cuenta y buscando áreas de contenido en las que esta diferencia no sea un gran obstáculo para poder hacer una comparación que no desfavorezca injustamente a la literatura. Lo mismo ocurre en la arquitectura y la escultura en las que el perfeccionismo detallista bajomedieval es considerado altamente estético, pero que tanto detalle en la literatura haría a ésta farragosa.

En literatura, el detallismo es nominalista, no adjetivista, y se logra a base de enumerar muchos sustantivos, no a base de elegir bien los adjetivos ni la manera en cómo se usan las palabras. Por contra, en el caso de la pintura lo mejor está en los pequeños detalles y en lo secundario del motivo del cuadro, que es donde el pintor tiene más libertad, porque en los protagonistas y contenidos principales no puede desviarse de las reglas establecidas, ya que llamaría la atención y sería mal visto por los convencionalismos de la época. En la literatura es al revés, pues es el guión principal el que atrae la atención, no los detalles del relato. La literatura además tiene extensión indefinida, mientras que la pintura y la escultura tienen la extensión que tenga el cuadro o la escultura, lo que pone límites al detallismo del artista. Por el contrario, si el escritor detalla mucho su relato, éste se vuelve demasiado extenso, consume tiempo del lector y acaba haciéndose fastidioso. El brillo, tan buscado en la última Edad Media, se refleja más fácilmente en la pintura que en la escritura. El pintor puede depositar en la forma y los detalles toda su sensibilidad y sus ideas, sin verse atormentado por ver cómo expresarlos en palabras que cumplan con las convenciones de la época. Aún así, hay algunas áreas en las que la literatura bajomedieval es superior a la pintura como, por ejemplo, cuando se busca expresar la burla, la sátira, la ironía. Huizinga se regodea en sus explicaciones sobre las características de cada fuente y en cómo limitan o favorecen la expresión de sensibilidades específicas, lo que acaba siendo una verdadera lección de crítica histórica. 


\section{Conclusiones Y REFLEXIONES}

Los temores o prevenciones que historiadores como Michel Vovelle ${ }^{18} \mathrm{y}$ George Duby ${ }^{19}$ expresaron contra la tentación de ver el estudio de las mentalidades como un camino mistificador, como un territorio extranjero al historiador, como algo exótico sin conexión alguna con la historia social, parecieran no ser tan graves ni peligrosos, siempre y cuando se mantenga el mínimum de rigor, erudición y ética requerido en todo trabajo de investigación. No en vano, tanto Huizinga como El otoño de la Edad Media parecen ahora encajar muy bien dentro de lo que las últimas generaciones de los Annales, con Jacques Le Goff a la cabeza, postularon como una nueva historia que abarcaría desde las representaciones, las ideologías y las mentalidades hasta lo imaginario y lo simbólico, sin renunciar incluso a abordajes psicoanalíticos. ${ }^{20}$ Le Goff mismo consideró que había que prestar especial atención a esos comportamientos paroxísticos o marginales que nos abren las puertas a la relación entre el mundo sensible y el sobrenatural, entre lo corporal y lo psíquico y en la que las fuentes privilegiadas del historiador son los documentos literarios y artísticos. ${ }^{21}$

En esta revalorización, podría argumentarse también si Huzinga y su Otoño... no enseñarían una vía paralela, equivalente pero diferente, al estudio de la historia propuesta por Foucault y otros, en donde la investigación del fenómeno se hace prestando atención a lo que el documento oculta más que a lo que muestra, a lo que implícitamente proyecta, más que a lo que directamente explicita. Foucault estructura el estudio del pasado en torno a las prácticas donde los hombres vieron verdades y sus luchas alrededor de estas verdades, en una arqueología donde lo que se ve es la punta del iceberg que explica también lo que no se ve. ${ }^{22}$ ¿No fueron Huizinga y

18 Michel Vovelle, Ideologías y mentalidades, Barcelona, Ariel, 1985. Ver apéndice de textos seleccionados en Blas Casado Quintanilla, coord., Tendencias historiográficas..., 2004.

19 Georges Duby, «La rencontré avec Robert Mandrou et l'elaboration de la notion d'histoire des mentalités», en Melanges Robert Mandrou. Histoire social, sensibilités collectives et mentalités. París, PUF, 1985, pp. 33-35. Ver apéndice de textos seleccionados en Blas Casado Quintanilla, coord., Tendencias historiográficas..., 2004, pp. 401 y 402.

20 Jacques Le Goff, Pensar la historia. Modernidad, presente, progreso. Barcelona, Paidós, 2005.

21 Jacques Le Goff, «Las mentalidades. Una historia ambigua, en Hacer historia. III. Nuevos temas, Barcelona, Laia, 1980. Referido en Blas Casado Quintanilla, Tendencias historiográficas... en apéndice de textos seleccionados.

22 Jacques Le Goff, Pensar la historia. Modernidad, presente, progreso. Barcelona, Paidós, 2005.

STVDIVM. Revista de Humanidades, 22 (2016) ISSN: 1137-8417, pp. 37-60 
El otoño de la Edad Media ejemplos de esto mismo, sólo que con un abordaje diferente? Así como se pueden usar herramientas de análisis tomadas de la lingüística podrían también tomarse modelos y herramientas de análisis provenientes del mundo de las artes y las letras, con todo el simbolismo que éste puede acarrear y con el que habrá que lidiar, pero que sería triste y miedoso ignorar bajo absolutos pretextos cientificistas. Existe entre buena parte de los historiadores una cierta animadversión al uso de la psicología como ciencia auxiliar, ${ }^{23}$ temerosos tal vez de que ella de pie al ejercicio de la subjetividad y de la falsificación histórica ${ }^{24}$ pero ¿cómo evitarlo si lo que se pretende es hacer de la historia el estudio de los estados de espíritu propios de cada época que propone Huizinga y de la que $E l$ otoño de la Edad Media es fiel exponente? ¿Cómo no recurrir a la subjetividad si se asume que la vivencia de lo histórico es el verdadero factor del conocimiento histórico, si «la historia es una resurrección que se opera en la esfera de los sueños, una visión de figuras inaprensibles, un oír palabras entendidas a medias?».25

Al reflexionar sobre «El otoño de la Edad Media» y la heurística y hermenéutica que Huizinga plantea, siempre habrá que estar pendiente del peligro de caer en lo que algunos de sus críticos han señalado como una simple mezcla de percepciones afortunadas sobre algunos aspectos de la civilización con paralelos o aproximaciones completamente ficticios ${ }^{26}$. Es la eterna discusión del historiador sobre si la propuesta histórica es o no inseparable de su autor, ${ }^{27}$ que en el caso de Huizinga adquiere un especial significado.

23 En gran parte estos temores tienen que ver con el enfoque psicoanalítico (Geoffrey Cooks y Travis Crosby, Psychohistory. Readings in the method of psychology, psychoanalysis and history. Binghamton, Yale University Press, 1987), pero existen otras escuelas de pensamiento dentro de la psicología con enfoques menos especulativos y más próximos a los de las ciencias experimentales: véase Rubén Ardila, «Psicohistoria. La perspectiva psicológica», Revista Latinoamericana de Psicología, 24/3 (1992), pp. 324-331, o Cristian Tileaga y Jovan Byford, Psychology and history. Cambridge, Cambridge University Press, 2014.

24 José Carlos Bermejo Barrera, Introducción a la historia teórica, Madrid, Akal, 2009.

25 Johan Huizinga, El concepto de la historia, México, FCE, 1977, p. 56

26 Jacques Heers, La invención de la Edad Media. Barcelona, Grijalbo Mondadori, 1995.

27 César Moheno, «El otoño de la Edad Media. Estudio sobre las formas de vida y el espíritu durante los siglos XIV y XV en Francia y en los Países Bajos. Madrid, Revista de Occidente, 1979». Reseña bibliográfica incluida en la sección «Crítica de Libros» de la revista mexicana Relaciones. Estudios de Historia y Sociedad, II/6 (prim. 1981), pp. 152-163. Disponible en red. 


\section{REFERENCIAS BIBLIOGRÁFICAS}

Alted Vigil, Alicia, 2004, «Historia de la cultura». En Blas Casado Quintanilla, coord., Tendencias historiográficas actuales. Madrid, Universidad Nacional de Educación a Distancia: 321-330.

ARDILA, Rubén, 1992, «Psicohistoria. La perspectiva psicológica». Revista Latinoamericana de Psicología, 24/3 (1992): 324-331.

Aurell, Jaume, 2013, «La historiografía medieval: siglos IX al XV». En Jaume Aurell, Catalina Balmaceda, Peter Burke y Felipe Soza, Comprender el pasado. Una historia de la escritura y el pensamiento histórico. Madrid, Akal: 94-142.

Aurell, Jaume, Catalina Balmaceda, Peter Burke y Felipe SozA, 2013, Comprender el pasado. Una historia de la escritura y el pensamiento histórico. Madrid, Akal.

Aurell, Jaume y Peter Burke, 2013, «De entresiglos a la década de los setenta: la reacción frente al positivismo». En Jaume Aurell, Catalina Balmaceda, Peter Burke y Felipe Soza, Comprender el pasado. Una historia de la escritura y el pensamiento histórico. Madrid, Akal: 237-285.

Aurell, Jaume y Peter Burke, 2013, «El siglo de la historia: historicismo, romanticismo y positivismo». En Jaume Aurell, Catalina Balmaceda, Peter Burke y Felipe Soza, Comprender el pasado. Una historia de la escritura y el pensamiento histórico. Madrid, Akal: 199-235.

Bermejo BARrera, José Carlos, 2009, Introducción a la historia teórica. Madrid, Akal.

BRAUdel, Fernand, 2002, Las ambiciones de la historia. Barcelona, Crítica.

Carbonell, Charles-Olivier, 1986, La historiografía. México, Fondo de Cultura Económica.

Casado Quintanilla, Blas, coord., 2004, Tendencias historiográficas actuales. Madrid, Universidad Nacional de Educación a Distancia.

CoOKs, Geoffrey y Travis Crosby, 1987, Psychohistory. Readings in the method of psychology, psychoanalysis and history. Binghamton, Yale University Press.

DubY, Georges, 1985, «Entretien avec Geroges Duby. La rencontre avec Robert Mandrou et l'elaboration de la notion d'histoire des mentalités». En Histoire sociale, sensibilités collectives et mentalités. Mélanges Robert Mandrou. París, PUF: 33-35.

Freijomil, Andrés, 2009, «Un historiador del ocaso. Los derroteros intelectuales del primer Huizinga (1897-1919)». Prismas. Revista de Historia Intelectual, 13/1 (jun. 2009): 33-64 Disponible en red.

HeErs, Jacques, 1995, La invención de la Edad Media. Barcelona, Grijalbo Mondadori.

HuizingA, Johan, 1977, El concepto de la historia. México, Fondo de Cultura Económica.

STVDIVM. Revista de Humanidades, 22 (2016) ISSN: 1137-8417, pp. 37-60 
HuizingA, Johan, 1982, El otoño de la Edad Media. Madrid, Alianza Universidad. (4. ${ }^{\mathrm{a}}$ edición).

LE GofF, Jacques, 1980, «Las mentalidades. Una historia ambigua». En Jacques Le Goff y Pierre Nora, dirs., Hacer historia. Vol. III. Nuevos temas. Barcelona, Laia: 81-97.

LE GofF, Jacques, 1991, «Johan Huizinga». En André Burguière, dir., Diccionario de ciencias históricas, Madrid, Akal: 350.

LE Goff, Jacques, 2005, Pensar la historia. Modernidad, presente, progreso. Barcelona, Paidós.

Martínez Shaw, Carlos, 2004, «Historia moderna». En Blas Casado Quintanilla, coord., Tendencias historiográficas actuales. Madrid, Universidad Nacional de Educación a Distancia: 233-284.

Moheno, César, «Reseña de libros. El otoño de la Edad Media. Estudio sobre las formas de vida y el espíritu durante los siglos XIV y XV en Francia y en los Países Bajos». Relaciones. Estudios de Historia y Sociedad, II/6: 152-163.

Myers, Jorge, 2002, «Historia cultural». En Carlos Altamirano, dir., Términos críticos de sociología de la cultura. Buenos Aires, Paidós: 126-128.

TileagA, Cristian y Jovan ByFord, 2014, Psychology and history. Cambridge, Cambridge University Press.

Valero Moreno, Juan Miguel, 2008, «Johan Huizinga. Ver la historia». En Javier San José Lera, Francisco Javier Burguillo y Laura Mier, coords., I Congreso Internacional de la Sociedad de Estudios Medievales y Renacentistas (Salamanca, 2006). Salamanca, Seminario de Estudios Medievales y Renacentistas: 439457.

Vovelle, Michel, 1985, Ideologías y mentalidades, Barcelona, Ariel. 